NBER WORKING PAPER SERIES

\title{
LABOR MARKET DYNAMICS WHEN UNEMPLOYMENT IS A WORKER DISCIPLINE DEVICE
}

Miles S. Kimball

Working Paper No. 2967

\author{
NATIONAL BUREAU OF ECONOMIC RESEARCH \\ 1050 Massachusetts Avenue \\ Cambridge, MA 02138 \\ May 1989
}

This paper is part of NBER's research programs in Economic Fluctuations and Labor Studies. Any opinions expressed are those of the authors not those of the National Bureau of Economic Research. I would like to thank Larry Summers, David Romer, Larry Katz, Greg Mankiw, Alan Krueger and Dan Nelson for helpful discussions, and participants in many seminars for helpful suggestions. 
NBER Working Paper \#2967

May 1989

\title{
LABOR MARKET DYNAMICS WHEN UNEMPLOYMENT \\ IS A WORKER DISCIPLINE DEVICE
}

\begin{abstract}
Efficiency wage models of the effort elicitation type have important implications for labor market dynamics. These models have a wide array of discontinuous sunspot equilibria driven by extraneous variables, in addition to well-behaved equilibria characterized by continuous, slowly. adjusting patterns of employment. Many aspects of actual labor markets can be replicated by these models. For example, the longer-run movements they predict in employment allow macroeconomic evidence for a large labor supply elasticity to be reconciled with panel data evidence for a small labor supply elasticity. Many testable, but as yet untested predictions about labor market dynamics can also be generated.
\end{abstract}

Miles S. Kimball Department of Economics University of Michigan Ann Arbor, MI 48109 


\section{Introduction}

Encouraged by a belief in genuinely involuntary unemployment, many economists have turned in recent years to "efficiency wage" theories as descriptions of the labor market. Despite serious criticisms, these theories-emphasizing the positive incentive effects of high wages that may induce firms to set non-market-clearing wages-remain some of the more promising ways of modelling labor markets beset by unemployment and underemployment.

One of the main variants on the theme of efficiency wages is the effort elicitation model, ${ }^{1}$ set out in its canonical form by Shapiro and Stiglitz (1984). Many authors have used a version of this model to examine various issues. ${ }^{2}$ One of the important limitations on the use of this model has been the lack of an adequate analysis of its dynamics outside of the steady state. ${ }^{3}$ The objective of this paper is to provide such an analysis of the dynamics of this type of efficiency wage model and to address some of the key questions about an efficiency-wage labor market that depend on such an analysis.

The first important question is: how, in theory, should an efficiency-wage labor market react to shocks? Is there a propagation mechanism for shocks peculiar to the effort elicitation model? This question is motivated by the literature on real business cycles. Second, what is the relationship between the macroeconomic labor supply elasticity implied by an effort elicitation model and that implied by the corresponding competitive model of the labor market? This question is important both for Real Business Cycle theory and for the Neo-Keynesian theory of price rigidity. Finally, the efficiency wage literature itself has raised the question of how one should test efficiency wage models empirically. In this context, the question is whether the dynamic properties of the effort elicitation model provide any way of empirically testing for that model.

Real business cycle theorists have been at pains to discover the reasons for the persistence of business cycle movements; in particular, they have raised the question of how the serial correlation properties of shocks should be related to the serial correlation properties of the business cycle movements they cause. Production, delivery and construction lags, as well as input-output relationships

\footnotetext{
1 See Katz (1986), who calls this variant "The Shirking Model."

2 See the references in Katz (1986).

3 Some authors, such as Bulow and Summers (1986), have made guesses about the nature of the dynamic equilibria of these models, but did not completely realize the subtlety of the problem, which-as will be seen below-involves multiple dy namic equitibria.
} 
among various industries, are cited as mechanisms by which business cycle movements can be more persistent than the shocks that cause them. ${ }^{4}$ But the workings of the labor market seem just as natural a place to look for a propagation mechanism that might help explain cyclical persistence. In particular, one might think that lags in the adjustment of employment levels to current demand conditions might contribute to the persistence of business cycle movements. This is, in fact. one of the predictions of the canonical effort elicitation model, as will be shown below.

Real business cycle theorists have also made great efforts to explain the high labor supply elasticities that seem to be evidenced in macro-data in the face of strong evidence for relatively low microeconomic labor supply elasticities. ${ }^{5}$ Indeed, Prescott's (1986) title "Theory thead of Business Cycle Measurement," seems to reflect at least in part his exultation over the fact that real business cycle theory has finally been able to predict higher macroeconomic labor supply elasticities than those indicated by macroeconomic data. A divergence between the microeconomic elasticity of labor supply and the macroeconomic elasticity of labor supply requires some kind of variation in the number of workers working. Real Business Cycle Models essentially rely on variation in labor-force participation to explain why the macroeconomic labor supply elasticity exceeds the microeconomic labor supply elasticity. By contrast, efficiency wage models focus primarily on variation in the involuntary unemployment rate to explain why the macroeconomic labor supply elasticity exceeds the microeconomic labor supply elasticity.

The hope of using efficiency wage models to explain the coexistence of apparently large aggregate labor supply elasticities and the small individual labor supply elasticities found when using panel data lends extra importance to an understanding of the lagged response of employment to demand conditions mentioned above. Because of this lagged response of employment, the macroeconomic labor supply elasticity in the very short run is the same as the labor supply elasticity for an individual. However, within a few quarters (according to what seems a reasonable calibration),

4 See for example Long and Plosser (1983) and Kydland and Prescott (1982).

5 Large macroeconomic labor supply elasticities are not only necessary in order to explain the data about business cycle movements, they are also a key element in the Neo-Key nesian theory of nominal price rigidity. Ball and Romer (1987) show that a large macroeconomic labor supply elasticity greatly reduces the pressure on firms to adjust their nominal prices in response to changes in demand, making it much more plausible that small costs of changing a nominal price could lead large monetary non-neutralities. While the model below has no costs of changing a nominal price and therefore exhibits monetary neutrality, it represents a situation ripe for small - nominal rigidities of that type to have important effects. Adding small costs of changing prices to the model below is an important topic for future research. 
employment levels will adjust, leading to a larger medium and long-run labor supply elasticity. Thus, effort elicitation models can help explain large aggregate labor supply elasticities at business cycle frequencies, but could not explain higher labor supply elasticities if they were found at frequencies much higher than that.

Any empirical test that can provide evidence for or against the effort elicitation model is potentially valuable because this model has many striking and important implications for industrial policy, trade policy, and the desirability of unemployment insurance and of affirmative action not shared by competing theories. ${ }^{6}$ The results presented below indicate that in a labor market described by the effort elicitation model we should find (a) that the overall rate of hiring in the labor market affects individual firms' labor costs, and (b) that aggregate employment is a distributed lag of demand conditions, with the length of the lag structure varying with the parameters of the model in a way that can be precisely specified.

The remainder of the paper will proceed as follows. Section II discusses the dynamics of the basic Shapiro-Stiglitz model, assuming that employment follows a continuous path over time. Section III shows that other dynamic equilibria exist, in which employment follows a discontinuous path; however, it is argued that these discontinuous equilibria are of interest primarily as a theoretical curiosity, and should be left to one side when discussing the empirical applications of the model. Section IV modifies the basic Shapiro-Stiglitz model by allowing for movements in hours per worker per week ${ }^{7}$ as well as in employment, with the object of calculating a rough but realistic estimate of the lag length and the short- and long-run macroeconomic labor supply elasticities. Section $\mathrm{V}$ reinterprets the model as a story about involuntary underemployment in the secondary sector of a dual labor market rather than as a story about involuntary unemployment and makes an estimate of the lag length and the short-and long-run labor supply elasticities given that interpretation. It is found that the model is much more helpful in explaining cyclical persistence and high macroeconomic labor supply elasticities under this interpretation. Section VI is the Conclusion.

\section{The Dynamics of the Shapiro-Stiglitz Model}

\footnotetext{
6 See, for example, the policy implications mentioned in Shapiro and Stiglitz (1984) and in Bulow and Summers (1986).

7 If fixed costs per day of work are important, most of the movement in hours per worker per week should come from movements in the average number of days worked per week.
} 
In this section we will use exactly the model described by Shapiro and Stiglitz (1984), where a detailed description of the model can be found. ${ }^{8}$ In examining out-of-steady state dynamics, we will begin by looking for dynamic equilibria in which employment follows a continuous path (but in which wages may jump), deferring to Section III a discussion of dynamic equilibria involving sudden jumps in employment. We will assume the existence of a representative firm, which is an inessential simplification when looking at the steady state, but is an important restriction outside the steady state. ${ }^{9}$

Shapiro and Stiglitz' fundamental asset equation for an employed shirker is their equation (1):

$$
r V_{E}^{S}=w+(b+q)\left(V_{u}-V_{E}^{S}\right)
$$

They describe this equation as "interest rate times asset value equals flow benefits (dividends) plus expected capital gains (or losses)." The "asset value" $V_{E}^{S}$ is expected discounted value of utility for an employed shirker. The "flow benefit" is the wage $w$. The expected "capital gain" (actually a loss) is the probability of job loss for a shirker $b+q$, where $b$ is the exogenous separation rate and $q$ is the probability of being caught shirking, times the amount of utility lost by becoming unemployed $V_{u}-V_{E}^{S}$.

Out of steady state, the only modification needed is to add the rate of change in $V_{E}^{S}$ itself to expected "capital gain." Thus, we have

$$
r V_{E}^{S}(t)=w(t)+(b+q)\left(V_{u}(t)-V_{E}^{S}(t)\right)+\dot{V}_{E}^{S}(t)
$$

Though it may not be obvious, writing the equation in terms of a rate of change implicitly assumes that $V_{E}^{S}(t)$ follows a continuous path, which, we will see, depends on employment following a continuous path. ${ }^{10} \mathrm{~A}$ similar remark applies to the other equations in this section.

Shapiro and Stiglitz' fundamental asset equation for an employed nonshirker is

$$
r V_{E}^{N}=w-\bar{e}+b\left(V_{u}-V_{E}^{N}\right)
$$

The treatment in this section owes a great deal to suggestions of David Romer's.

9 The main problem that would arise in the absence of a representative firm is that some firms might well be laying off workers even while aggregate hiring is positive.

10 Tecbnically, we are assuming piecewise differentiability of $V_{E}^{S}(t)$ as well. However, with enough mathematical machinery, this differentiability assumption can be relaxed. The key assumption is continuity. 
where $V_{E}^{N}$ is the expected discounted value of utility for an employed nonshirker and $\bar{e}^{-11}$ is the disutility of working instead of shirking. (The probability of job separation for a nonshirker is just the exogenous separation rate b.) To allow for out-of-steady state dynamics, we need to include the expected change in $V_{E}^{N}$ as part of the capital gain term, yielding

$$
r V_{E}^{N}(t)=w(t)-\bar{e}+b\left(V_{u}(t)-V_{E}^{N}(t)\right)+\dot{V}_{E}^{N}
$$

The no-shirking condition is $V_{E}^{S} \leq V_{E}^{N}$. If a firm was considered absolutely trustworthy by workers, it would be possible for a firm to put off or defer workers' wages in such a way that $V_{E}^{S}<V_{E}^{N}$ without adversely affecting the firm's profits. However, Shapiro and Stiglitz assume that firms cannot be trusted, in order to rule out bonding schemes in which a worker pays an employment fee to get a job and then is motivated by the fear of having to pay another employment fee to get another job if he or she is fired. If firms are perceived as untrustworthy enough that such a bonding scheme cannot work despite the great potential benefits of such an arrangement to both workers and firm, it is clear that the perception of the firm as untrustworthy will make workers loath to accept a situation in which the firm could gain by replacing workers to whom it had made an implicit but not legally binding promise of higher wages later. Since by Shapiro and Stiglitz' assumption that once working rather than shirking, a worker cannot work any harder, there is no gain to the firm in having $V_{E}^{N}$ strictly greater than $V_{E}^{S}$ to counterbalance even a small cost due to workers' distrust of its motives, and therefore, a firm should keep the utility for a shirker and for a nonshirker exactly equal at all times:

$$
V_{E}^{S}(t)=V_{E}^{N}(t) \quad \text { for all } t
$$

Since this is true for all values of $t$, we also have

$$
\dot{V}_{E}^{S}(t)=\dot{V}_{E}^{N}(t) \quad \text { for all } t
$$

Subtracting (2') from (1'), and using (3) and (4) to simplify the result, yields

$$
V_{E}^{N}(t)=V_{u}(t)+\frac{\bar{e}}{q} \text { for all } t
$$

11 I have taken the liberty of adding a bar to Shapiro and Stiglitz' "e" in order to distinguish it from the base for natural logarithms. 
which $^{12}$ in turn implies

$$
\dot{V}_{E}^{N}(t)=\dot{V}_{u}(t) \quad \text { for all } t
$$

The expected discounted value of utility for an unemployed worker $V_{u}$ must obey the "asset" equation:

$$
r V_{u}(t)=\bar{w}(t)+a(t)\left(V_{E}^{N}-V_{u}\right)+\dot{V}_{u}(t)=\bar{w}(t)+a(t) \frac{\bar{e}}{q}+\dot{V}_{u}(t)
$$

where $\bar{w}(t)$ represents the instantaneous utility of an unemployed individual and $a(t)$ is the job acquisition rate. ${ }^{13}$ Substituting in from (5) and (6) to eliminate $V_{u}$ and $\dot{V}_{u}$ yields:

$$
r\left(V_{E}^{N}-\frac{\bar{e}}{q}\right)=\bar{w}(t)+a(t) \frac{\bar{e}}{q}+\dot{V}_{E}^{N}
$$

Together with (2') and (5), this implies

$$
w(t)=\bar{w}(t)+\bar{e}+(r+b+a(t)) \frac{\bar{e}}{q} .
$$

The job acquisition rate $a(t)$ can be determined from the employment flow identity

$$
\dot{L}(t)=a(t)(N(t)-L(t))-b L(t)
$$

where $N(t)$ is the size of the labor force. Rearranging, we have

$$
a(t)=\frac{\dot{L}(t)+b L(t)}{N(t)-L(t)}
$$

Therefore,

$$
w(t)=\bar{w}(t)+\bar{e}+\left[r+\frac{\dot{L}(t)+b N(t)}{N(t)-L(t)}\right] \frac{\bar{e}}{q},
$$

This is the dynamic version of Shapiro and Stiglitz" "No Shirking Condition," which in an effort elicitation model takes the place of the labor supply curve in the standard model of the labor market.

12 Equation (5) has the following interpretation. To keep a worker from shirking at any given instant, the benefit per unit time from shirking, $e$, must be less than the cost per unit time, which is the probability of detection times the cost of job loss. Thus, $z \leq q\left(V_{E}-V_{u}\right)$. The argument ruling out a strict inequality and insuring that $V_{E}=V_{E}^{N}=V_{E}^{S}$ is as above.

13 There is no issue about what the expected discounted value of utility for a newly employed worker will be, since in equilibrium, no one shirks, and $V_{E}^{S}=V_{E}^{N}$ in any case. 
Turning this dynamic "No Shirking Condition" around, the rate of increase in employment can be viewed as a function of the current wage and the current level of employment:

$$
\dot{L}(t)=\left[\frac{q}{e}(w(t)-\bar{e}-\bar{w}(t))-r\right][N(t)-L(t)]-b N(t)
$$

On the demand side of the labor market, we can obtain a very simple dynamic demand relation if we are willing the make the simplifying assumption that the representative firm always has a positive gross hiring rate. Since labor market turnover is on the order of $30 \%$ per year, ${ }^{14}$ this assumption does not put any serious limitation on the size of shocks we can analyze. ${ }^{15}$ Given this assumption that gross hiring is always positive, the condition that the marginal product of labor is equal to the wage must hold at every point in time, since if the marginal product of labor were ever different from the wage, the firm could increase profits by delaying or accelerating the hiring of workers hired around that time. ${ }^{16}$ Aggregating across the labor market as in Shapiro and Stiglitz (1984), we have:

$$
w(t)=p(t) F^{\prime}(L(t)) \quad \text { for all } t,
$$

where $p(t)$ can be interpreted either as the price of the output of the firms sharing this labor market relative to the price of wage-goods, or as an indicator of shifts in productivity.

Equations (13) and (14) allow us to diagram the response of the labor market to shifts in $p(t)$, $N(t)$, the number of workers in the labor force, and $\bar{w}(t)$, instantaneous utility when unemployed. Figure 1 shows the effect of a permanent increase in the relative price of output or productivity $p(t)$ Figure 2 shows the effect of a permanent increase in $N(t)$. A fall in $\bar{w}(t)$ would have a qualitatively similar effect. Figure 3 shows the effect of a temporary increase in $p(t)$. There is nothing wrong with having an anticipated sudden decline in the wage as depicted in Figure 3; the fact that employment suddenly begins to decline after $p(t)$ returns to its original value keeps workers motivated despite the suddenly lower wage.

14 See Medoff (1979).

15 The unattractive implication that layoffs do not occur should not be blamed on this assumption. It is much more the result of the assumption of a representative firm than it is of the assumption that aggregate employment will not contract at a rate faster than the turnover rate.

16 By delaying or accelerating the hiring of workers, and making a slight adjustment for the resulting change in the pattern of employee attrition, the firm can employ a little more labor at that instant without altering the amount of labor it employs at other instants. 
Under the assumption of rational expectations, the results above can easily be extended to handle macroeconomic uncertainty (in addition to the microeconomic uncertainty about how long it would take for a worker to get caught shirking or to quit exogenously), while still ruling out any discontinuities in the overall level of employment. To carry out the extension to the case of macroeconomic uncertainty, $\dot{V}_{E}^{S}, \dot{V}_{E}^{N}$ and $\dot{V}_{u}$ in (1'), (2'), (7) and (8) need to be replaced with their expected values. But by the same arguments as those given for them above, (3)-(6) and (9)-(14) should hold unaltered not only at all dates but also in every state of nature. ${ }^{17}$ Regardless of the complexity of macroeconomic uncertainty, there will be a dynamic stochastic equilibrium in which employment follows a continuous path, since given any current level of employment, moving along the shifting Marginal Productivity Condition at a velocity determined by the shifting *No Shirking Condition" will satisfy both conditions.

Several key implications of the model are already apparent. First, as is clear from the figures. (13) indicates a lagged response of employment to demand conditions. Intuitively, the reason for this adjustment lag in employment is that in a boom, a firm is reluctant to hire workers when all the other firms are also hiring, since the motivation of workers who see so many "help-wanted" ads around them will be impaired unless they get extra-high wages. Thus, each firm tries to delay hiring extra workers, which moderates the overall rate of hiring in the labor market. In a recession. a firm is not so eager to reduce its labor force if it suddenly becomes easier to motivate its workers due to reductions in employment and therefore dismal job prospects elsewhere. This fact tends to moderate the aggregate rate of reduction in employment. ${ }^{18}$

Second, a macroeconomic labor supply elasticity exceeding the microeconomic labor supply elasticity is insured by the long run responses of employment to changes in demand, since so far we have assumed a microeconomic labor supply elasticity of zero. ${ }^{19}$ Third, it is clear that the overall rate of hiring in the labor market affects individual firm's labor costs. ${ }^{20}$

17 We must, however, assume that each firm is hiring not only at all dates but also in all states of nature to insure that (14) holds at all dates in all states.

1t If the changes in employment can occur instantly, as in the next section, this reasoning no longer holds, since a specific disturbance is over before it has a chance to affect worker motivation ex post, although the prospect of such a sudden change in employment does affect the wage it ex ante, as shown below.

19 Here we are referring to the supply of hours, and not the supply of effort, which is quite elastic.

20 The lag lengths and elasticities implied by this model could readily be calculated, but it is better to wait and calibrate the model after we have added the decision about weekly hours. 
Finally, one can see that after a permanent shock to labor demand the wage $w$ initially overshoots the value it has in the new steady state, during the period when the hiring rate is especially high. On its face, this result seems to call the effort elicitation model into question, since there is little evidence that the wage overshoots in response to shocks. However, one could argue that $w$ represents implicit labor costs first and wages only secondarily, and that labor costs may exhibit this kind of overshooting pattern even if wages follow a gradual, monotonic adjustment path in reponse to a shock. The difference in the response of labor costs and the wage might result from variation in non-pecuniary benefits (e.g. whether the boss remembers to bring the secretary a birthday gift may depend on how many other job openings there are for secretaries right then) or from the deferral of promised wage payments until the next regularly scheduled date for raises.

\section{Dynamic Equilibria with Sudden Jumps in Employment}

Though uncertainty by itself does not change the overall character of the equilibria, allowing sudden jumps in employment-when joined with uncertainty about the timing of such jumps ${ }^{21}-$ drastically changes the character of the possible equilibria of the model. As a description of labor markets in our world, the sudden, synchronized labor-market-wide jumps in employment necessary for these discontinuous equilibria seem implausible. In practice, there are likely to be both serious difficulties of synchronization across firms in both the timing and magnitude of a jump in hiring that point to following a continuous path of employment as a "focal point" equilibrium, ${ }^{22}$ and costs associated with the rate of hiring which may be insignificant at any normal rate of hiring, but are important when considering the sudden hiring of many employees at once, tending to rule out the model's discontinuous equilibria. ${ }^{23}$ However, to those who believe that sudden, synchronized, labor-market-wide jumps in employment are possible, the model we are using presents an interesting

21 We cannot analyze perfectly anticipated jumps in employment in the framework here since by (12) the cost of having a worker at the instant of the anticipated jump would be infinite. As a result, the firm would want to rid itself of workers immediately before that instant and the assumption that the hiring rate is always positive could not be maintained.

22 See Schelling (1960) for a discussion of "focal points" in game theory. In conversation, Larry Summers has argued for immediate adjustment to a new steady state as the "focal point" equilibrium. However, there is a clean solution of this form only when there is only a single, permanent shock. Given a shock of any other shape, since there must be some adjustment after an initial jump of any size, the only size of initial jump that stands out from the rest is no initial jump at all.

23 The notion of hiring costs that are infinitesimal at any finite rate of hiring, but prohibitive at an infinite rate of hiring could be formalized (for example by making instantaneous profits equal to $F(L)-w L-\epsilon(b L+L)^{2}$ and by taking the limit of the solution as $\epsilon-0$ ), and would have no effect on the model except to reduce the set of equilibria to the single continuous equilibrium. 
array of "sunspot" equilibria driven by extraneous occurrences .

A full study of all of the sunspot equilibria is beyond the scope of this paper, but it is instructive to show how the equations are modified when sudden jumps in employment are allowed and to present a specific example of a sunspot equilibrium.

Let $\lambda(t)$ be the instantaneous probability of a sudden jump in employment at time $t$. conditional on all information available up to that time. Then together with the modification necessary to incorporate any uncertainty, (1') becomes

$$
r V_{E}^{S}(t)=w(t)+(b+q)\left(V_{u}(t)-V_{E}^{S}(t)\right)+\mathrm{E}_{\mathfrak{t}}^{0} \dot{V}_{E}^{S}(t)+\lambda(t) \mathrm{E}_{\mathrm{t}}^{*}\left[V_{E}^{S}\left(t^{+}\right)-V_{E}^{S}\left(t^{-}\right)\right] .
$$

where $E_{\mathfrak{t}}^{*}$ is an expectation conditional on a jump, $E_{\mathfrak{t}}^{0}$ is an expectation conditional on no jump. and. for simplicity, the assumption that the firm is always hiring and never has layoffs is still maintained. Similarly, (2') becomes

$$
r V_{E}^{N}=w-\bar{e}+b\left(V_{u}-V_{E}^{N}\right)+E_{\mathrm{t}}^{0} \dot{V}_{E}^{S}(t)+\lambda(t) \mathrm{E}_{\mathrm{t}}^{*}\left[V_{E}^{S}\left(t^{+}\right)-V_{E}^{S}\left(t^{-}\right)\right]
$$

It is still true that $V_{E}^{S}$ and $V_{\tilde{E}}^{N}$ must be equal at every date and in every state ((3) and (4)), which implies that their changes must be equal as well, even when a jump is involved, and since this implies that (5) still holds, at every date and in every state, these changes are always equal to those in $V_{u}$.

To allow for the possibility of jumps in employment, (7) must be modified to

$$
r V_{u}(t)=\bar{w}(t)+a(t) \frac{\bar{e}}{q}+E_{\mathfrak{t}}^{0} \dot{V}_{u}(t)+\lambda(t) E_{\mathfrak{t}}^{*}\left[V_{u}\left(t^{+}\right)-V_{u}\left(t^{-}\right)+\frac{L\left(t^{+}\right)-L\left(t^{-}\right)}{N\left(t^{-}\right)-L\left(t^{-}\right)}\right] \frac{\bar{e}}{q},
$$

where $a(t)$ is now the job acquisition rate in the absence of discontinuities in the level of employment.

The counterpart to (8) is

(18) $r\left(V_{E}^{N}(t)-\frac{\bar{e}}{q}\right)=\bar{w}(t)+a(t) \frac{\bar{e}}{q}+E_{\mathfrak{t}}^{0} \dot{V}_{E}^{N}(t)+\lambda(t) E_{\mathfrak{t}}^{*}\left[V_{E}^{N}\left(t^{+}\right)-V_{E}^{N}\left(t^{-}\right)+\frac{L\left(t^{+}\right)-L\left(t^{-}\right)}{N\left(t^{-}\right)-L\left(t^{-}\right)}\right] \frac{\bar{e}}{q}$,

the counterpart to $(9)$ is

$$
w(t)=\bar{w}(t)+\bar{e}+\left[r+b+a(t)+\lambda(t) E_{t}^{*} \frac{L\left(t^{+}\right)-L\left(t^{-}\right)}{N\left(t^{-}\right)-L\left(t^{-}\right)}\right] \frac{\bar{e}}{q},
$$

and the counterpart to (12) is

$$
w(t)=\bar{w}(t)+\bar{e}+\left[r+\frac{E_{t}^{0} \dot{L}(t)+b N(t)}{N(t)-L(t)}+\lambda(t) E_{t}^{*} \frac{L\left(t^{+}\right)-L\left(t^{-}\right)}{N\left(t^{-}\right)-L\left(t^{-}\right)}\right] \frac{\bar{e}}{q} .
$$


The only real change is the addition of the instantaneous probability of a jump, times the expected fraction of unemployed workers who will be hired if there is a jump, times the gain $\frac{\xi}{q}$ from becoming employed. In other words, in order to motivate workers, the firm has to pay according to the full expected probability of being rehired, including the chance of being rehired during a sudden jump in employment.

Given the assumption of positive hiring at every date and in every state, the equality of the wage and a worker's marginal value product at every date and in every state should still hold. Thus, the two equations that need to be satisfied are (20) and (14).

The following example will make clearer what such a sunspot equilibrium is like. Suppose that

$$
L(t)=\left[(1-b) e^{t}-b t+k\right] \frac{N}{e^{t}+1},
$$

where $t$ is the length of time that has elapsed since the last jump in employment, $k$ is a constant between $b$ and $b-1$ and $e$ (without the bar) is the base of natural logarithms. Let

$$
w(t)=\bar{w}+\bar{e}+\left[r+\lambda \phi+\frac{e^{t}}{e^{t}+1}\right] \frac{\bar{e}}{q}
$$

where $\bar{w}, \lambda$ and $\phi=\frac{L\left(t^{+}\right)-L\left(t^{-}\right)}{v-L\left(t^{-}\right)}$are constants. Then $L(t)$ and $w(t)$ satisfy (20), and equations (21) and (22) implicitly define a labor demand curve, which in turn yields an aggregate production function for which (14) is satisfied even when productivity or the relative price of output $p$ is always equal to 1 .

In the next section, we will again concentrate on the dynamic equilibrium involving a continuous path of employment, but it should be kept in mind that other equilibria involving jumps in employment may be possible.

\section{Adding the Hours Decision}

In explaining the fluctuation over the business cycle in total man-hours worked per unit time, variation in the number of hours per worker per week is of roughly equal importance with variation in the number of workers employed. ${ }^{24}$ To allow our model to represent this fact accurately, we need to allow a decision about hours per worker per week. To keep things simple, we will (a) look

\footnotetext{
24 See Prescott (1986).
} 
at only the dynamic equilibrium in which employment follows a continuous path, (b) assume that the number of hours per worker per week is chosen unilaterally by the firm (although the workers decide whether to put forth any effort during those hours), and (c) restrict the way in which a worker's utility and the chance of detection as a shirker in the model can depend on weekly hours per worker, as follows.

It seems reasonable to suppose that the disutility of effort is proportional to the number of hours over which that effort must be exerted, but that there is also a disutility of having to be present at the workplace for a given length of time that is separate from the disutility of effort. Therefore, let us assume that a worker's instantaneous utility when working is equal to $h(t)(w(t)-\bar{e})-\phi(h(t))$, where $h$ is the number of hours per week, $w$ is now the hourly wage, and $\phi(h)$ is the disutility from having to be physically present at work $h$ hours per week. The marginal disutility of hours at work should be positive and increasing in $h$, so we will assume further that $\phi^{\prime}(h)>0$ and $\phi^{\prime \prime}(h)>0$. It also seems reasonable to assume that the probability of detection as a shirker should be proportional to the number of hours spent at work. But then the probability of an error falsely labelling someone as a shirker should also be proportional to the number of hours at work. Therefore, let us assume that the instantaneous probability of separation for a nonshirker is $b+c h(t)$, where $b$ is the probability of separation for exogenous reasons as before and $c h(t)$ is the probability of being falsely labelled as a shirker or "false positive rate." For a shirker, let us assume that the instantaneous probability of separation is $b+c h(t)+q h(t)$ where $q h(t)$ is the weekly "detection rate" or additional probability of being labelled a shirker due to actually being a shirker.

Given these specifications of the instantaneous utility function and the instantaneous probabilities of separation for shirkers and nonshirkers, we can modify (1') to

$$
r V_{E}^{S}(t)=h(t) w(t)-\phi(h(t))+(b+c h(t)+q h(t))\left(V_{u}(t)-V_{E}^{S}(t)\right)+\dot{V}_{E}^{S}(t)
$$

and we can modify $\left(2^{\prime}\right)$ to

$$
r V_{E}^{N}(t)=h(t)(w(t)-\bar{e})+(b+c h(t))\left(V_{u}(t)-V_{E}^{N}(t)\right)+\dot{V}_{E}^{N}
$$

Because of these specifications, (3)-(8) will continue to hold as written, (5) now arising from subtracting (24) from (23) and dividing by $h$. 
In place of (9) we now have 25

$$
w(t)=\frac{\phi(h(t))+\bar{w}(t)+[r+b+a(t)] \frac{\bar{s}}{q}}{h(t)}+\bar{e}+c \frac{\bar{e}}{q} .
$$

But $h(t)$ is a choice variable for the firm. Since an atomistic firm can hire workers to get as mucl labor as it wants at the hourly wage $w(t)$ determined by (25), the firm's objective in choosin weekly hours per worker, $h(t)$, is simply to minimize the current cost of labor, $w(t)$. The first-orde condition for minimizing the right-hand side of (25) with respect to $h$ can be written

$$
h(t) \phi^{\prime}(h(t))-\phi(h(t))=\bar{w}+[r+b+a(t)] \frac{\bar{e}}{q} .
$$

Because of the convexity of $\phi(h)$, the quantity $h \phi^{\prime}(h)-\phi(h)$ is a monotonically increasing functio of $h$, which in turn implies that the optimal value of $h(t)$ is a monotonically increasing function $c$ the fixed cost of a worker, $\ddot{w}+[r+b+a(t)] \frac{e}{q}$, which is an exogenous variable from a single firm point of view.

Substituting from (26) into (25), we discover further that

$$
w(t)=\phi^{\prime}(h(t))+\bar{e}+c \frac{\bar{e}}{q}
$$

In words, (27) states that on the margin, the hourly wage must exactly compensate for the margin: disutility of working an extra hour, comprised of the marginal disutility of being physically preser on the job an extra hour, the disutility of exerting effort for another hour, and the expected utilit loss due to the danger of being falsely labelled a shirker as a result of working an extra hou Equation (27) implies that, holding the level of effort fixed, workers would choose the same weekl hours as the firm chooses for them. Thus, the firm's authority to choose weekly hours will not be serious bone of contention with the workers. However, since the level of effort is not fixed, it is sti important for the firm to choose weekly hours, since workers allowed to choose weekly hours an their own effort jointly might well choose the combination of relatively low hours and low effort.

We can invert (27) to obtain

$$
h(t)=H(w(t))=\phi^{\prime-1}\left(w(t)-\bar{e}-c \frac{\bar{e}}{q}\right) .
$$

25 Note that while $w(t)$ is now an bourly quantity, the unemployment benefit $\bar{w}(t)$ is still a weekly quantity ib does not depend on $h(t)$. 
Recognizing that now

$$
a(t)=\frac{\dot{L}(t)+[b+c h(t)] L(t)}{N(t)-L(t)}
$$

we can substitute from (28) and (29) into (25) to obtain a counterpart to (12):

$$
w(t)=\frac{\phi(H(w(t)))+\bar{w}(t)+\left[r+\frac{\dot{L}(t)+b+c H(w(t)) ! N(t)}{N(t)-L(t)}\right] \frac{e}{7}}{H(w(t))}+\bar{e},
$$

which defines $w(t)$ implicitly. ${ }^{26}$ Similarly, (14) can be modified to

$$
w(t)=F^{\prime}(H(w(t)) L(t))
$$

Graphically, the fact that weekly hours tend to increase with the wage flattens the curve showing the "Marginal Revenue Product Condition" and changes the slope of the curve showing the steady-state "No Shirking Condition," but otherwise leaves the pictures essentially the same. Changes in weekly hours can be seen directly in the graphs, since $h(t)$ is a monotonically increasing function of $w(t)$.

Analy tically, we can linearize around a steady state and solve the resulting differential equations as follows. Using asterisks to denote steady-state values and tildes to denote divergences from steady state values, the linearized version of $(30)$ is

$$
\begin{aligned}
\tilde{w}(t) & =\frac{\tilde{\bar{w}}(t)}{h^{*}}+\frac{\tilde{a}(t) \bar{e}}{q h^{*}} \\
& =\frac{\tilde{\bar{w}}(t)}{h^{*}}+\left[\frac{\dot{\tilde{L}}(t)}{N^{*}-L^{*}}+\left[b+c h^{*}\right] \frac{N^{*} \tilde{L}(t)-L^{*} \bar{N}(t)}{\left(N^{*}-L^{*}\right)^{2}}\right] \frac{\bar{e}}{q h^{*}}+\frac{c L^{*} \bar{e} \alpha}{\left(N^{*}-L^{*}\right) q w^{*}} \bar{w}(t),
\end{aligned}
$$

where $\alpha=\frac{H^{\prime}\left(w^{*}\right) w^{*}}{h^{*}}=\frac{w^{*}}{h^{-} \phi^{\prime \prime}\left(h^{-}\right)}$is the elasticity of weekly hours with respect to the wage. ${ }^{27}$ Linearizing (31) yields

$$
\begin{aligned}
\tilde{w}(t) & =p^{*} F^{\prime}\left(L^{*} h^{*}\right)\left[\frac{\tilde{p}(t)}{p(t)}+\frac{F^{\prime \prime}\left(L^{*}\right)}{F^{\prime}\left(L^{*}\right)}\left(h^{*} \bar{L}(t)+L^{*} H^{\prime}\left(w^{*}\right) \bar{w}(t)\right)\right] \\
& =w^{*}\left[\frac{\tilde{p}(t)}{p(t)}-\gamma \frac{\tilde{L}(t)}{L^{*}}-\alpha \gamma \frac{\tilde{w}(t)}{w^{*}}\right]
\end{aligned}
$$

28 We could use (26) and (27) to express $w(t)$ directly as a function of exogenous variables, but the approach used here leads to expressions more easily interpretable in terms of standard empirical quantities.

${ }^{27}$ The envelope theorem is helpful in obtaining (32). Since $h(t)$ is chosen to minimize $w(t)$, endogenous changes in $h(t)$ can be ignored when deriving a linear approximation like (32), except insofar as those endogenous changes in $h(t)$ affect $a(t)$, which is exogenous to an individual firm. Also, note that $\dot{L}(t)$ is zero in the steady state, but that $\dot{\bar{L}}(t)$ need not be zero. 
where $\gamma=-\frac{L^{\bullet} F^{\prime \prime}\left(L^{\bullet}\right)}{F^{\prime}\left(L^{\bullet}\right)}$ shows the degree of diminishing returns to labor. Isolating $\bar{w}(t) \cdot$ in $(32)$, we find that

$$
\bar{w}(t)=\frac{1}{1-\frac{c L^{*} \xi q}{\left(N^{*}-L^{*}\right) q \psi^{*}}}\left\{\frac{\tilde{\bar{w}}(t)}{h^{*}}+\left[\frac{\dot{\tilde{L}}(t)}{N^{*}-L^{*}}+\left[b+c h^{*}\right] \frac{N^{*} \tilde{L}(t)-L^{*} \bar{V}(t)}{\left(N^{*}-L^{*}\right)^{2}}\right] \frac{\bar{e}}{q h^{*}}\right\},
$$

as long as $\frac{c L^{*} \ell q}{\left(N^{*}-L^{-}\right) q w^{*}}<1 .{ }^{28}$ Isolating $\bar{w}(t)$ in (33),

$$
\bar{w}(t)=\frac{w^{*}}{1+\alpha \gamma}\left[\frac{\tilde{p}(t)}{p^{*}}-\gamma \frac{\tilde{L}(t)}{L^{*}}\right]
$$

Equating the right-hand sides of (34) and (35) yields a first-order differential equation that can be read off from those equations. To solve for a particular solution of this equation, we need a boundary condition. If we label the time when a disturbance to the steady state first becomes known as time zero, and follow the standard practice of taking steady-state values as initial conditions, then the equilibrium in which employment follows a continuous path is distinguished by the boundary condition $\bar{L}(0)=0 .{ }^{29}$ Solving the differential equation with this boundary condition. yields

$\tilde{L}(t)=\int_{0}^{t} e^{-\kappa(t-s)}\left[\frac{\left(b+c h^{*}\right] L^{*}}{N^{*}-L^{*}} \tilde{V}(s)+\left(\frac{h^{*} w^{*} q\left(N^{*}-L^{*}\right)}{\bar{e}}-\alpha c h^{*} L^{*}\right) \frac{\tilde{p}(s)}{(1+\alpha \gamma) p^{*}}-\frac{q\left(N^{*}-L^{*}\right) \tilde{\bar{w}}(s)}{\tilde{e}}\right] d$

where

$$
\kappa=\frac{\left[b+c h^{*}\right] N^{*}}{N^{*}-L^{*}}+\frac{\gamma w^{*} h^{*} q\left(N^{*}-L^{*}\right)}{(1+\alpha \gamma) \bar{e} L^{*}}-\frac{\alpha \gamma c h^{*}}{1+\alpha \gamma}
$$

Thus, to a first-order approximation, $\tilde{L}(t)$ is an exponentially distributed lag of the exogenous disturbances $\bar{p}(t), \bar{N}(t)$ and $\tilde{\bar{w}}$, with lag length $\kappa^{-1}$. Equation (36) can be substituted into (35) to find a lengthy expression for $\bar{w}(t)$ as well. Multiplying the expression for $\bar{w}(t)$ by $H^{\prime}\left(w^{*}\right)$ yields the linear approximation for $\tilde{h}(t)$. The path of output corresponding to the paths of employment and

28 If $\frac{c L^{*} 3 q}{\left(N^{-}-L^{-}\right) q w^{*}}>1$, then the equilibrium is unstable, since an increase in weekly hours increases turnover through increasing the frequency of workers being falsely labelled as shirkers, causing wages, and therefore hours, to rise still further, in a way that does not converge. To put it another way, as each firm tries to avoid the higher fixed costs per worker by extending weekly hours, the increased turnover has a negative spilbver effect on the motivation of workers at other firms, which raises the fixed cost per worker still further. There should be a stable equilibrium at a point with long enough working hours, since when the marginal disutility of

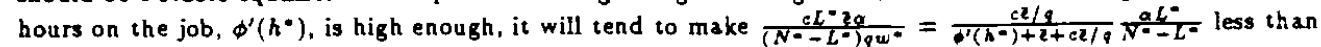
one.

29 Without the assumption that employment follows a continuous path, there would be many sunspot equilibria approximated by other particular solutions to the differential equation. 
wages given above is

$\frac{\bar{y}(t)}{y^{*}}=\frac{F^{\prime}\left(h^{*} L^{*}\right)}{y^{*}}\left[L^{*} H^{\prime}\left(w^{*}\right) \bar{w}(t)+h^{*} \dot{L}(t)\right]=\frac{w^{*} h^{*} L^{*}}{p^{*} y^{*}}\left[\alpha \frac{\tilde{w}(t)}{w^{*}}+\frac{\tilde{L}(t)}{L^{*}}\right]=\frac{w^{*} h^{*} L^{*}}{p^{*} y^{*}(1+\alpha \gamma)}\left[\alpha \frac{\bar{p}(t)}{p^{*}}+\frac{\tilde{L}(t)}{L^{*}}\right]$

Or, if the movement in $p$ represents a productivity shock rather than merely a relative price change, $\frac{j(t)}{p^{-}}$would have to be added to this expression for $\frac{i(t)}{y^{*}}$.

The quantities we are especially interested in are the convergence rate $\kappa$ given by $(37)$, with the lag length as its reciprocal, and the macroeconomic labor supply elasticities. Since employment adjusts slowly, the short-run macroeconomic labor supply elasticity is simply the elasticity of weekly hours per worker with respect to the wage, or $\alpha$. Observationally, this would be the microeconomic labor supply elasticity found when looking only at the variation in hours of employed workers. and not at movements into and out of employment. Estimates for this number center around approximately $.2 .^{30}$ The long-run macroeconomic labor supply elasticity is the sum of this elasticity of weekly hours with respect to the wage and the elasticity of employment along the steady-state “No Shirking Condition." This long-run wage elasticity of employment along the steady-state "No Shirking Condition," which will be denoted $\beta$, can be calcnlated from (36) and (3i) as the effect of a permanent shift in a horizontal labor demand curve from one wage to another. ${ }^{31}$ If we make the labor demand curve flat by setting $F^{\prime \prime}(\cdot)$ to zero, then $\frac{\Delta \psi}{w^{*}}=\frac{\Delta p}{p^{*}}$ and $\gamma=-\frac{F^{\prime \prime}\left(h^{*} L^{-}\right)}{F^{\prime}\left(h^{*} L^{-}\right)}=0$. Substituting in $\bar{N}(s)=0, \tilde{\bar{w}}(s)=0$ and $\tilde{p}(s)=\Delta p$, we then find that

$$
\Delta L=\lim _{t \rightarrow \infty} \tilde{L}(t)=\frac{N^{*}-L^{*}}{\left[b+c h^{*}\right] N^{*}}\left[\frac{q w^{*} h^{*}\left(N^{*}-L^{*}\right)}{\bar{e}}-\alpha c h^{*} L^{*}\right] \frac{\Delta p}{p^{*}},
$$

and

$$
\beta=\frac{\Delta L / L^{*}}{\Delta w / w^{*}}=\frac{\Delta L / L^{*}}{\Delta p / p^{*}}=\frac{q w^{*} h^{*}\left(N^{*}-L^{*}\right)^{2}}{\bar{e}\left[b+c h^{*}\right] N^{*} L^{*}}-\frac{\alpha c h^{*}\left(N^{*}-L^{*}\right)}{\left[b+c h^{*}\right] N^{*}} .
$$

From (37) it can be seen that the convergence rate $\kappa$ increases with the exogenous quit rate $b$, the weekly wage $w h^{*}$ and the hourly detection rate $q$, and falls with the disutility of effort $\bar{e}$, the elasticity of hours $\alpha$, and the false positive rate $c h^{*}$. If $c h^{*}$ is relatively small, the convergence rate

30 See the estimates for the intertemporal elasticity of substitution in iabor supply in Pencavel (1986), which seem appropriate for studying movements in labor supply over the businese cycle.

31 Though the labor demand curve is downward sloping rather than horizontal, in the tradition of demand and supply analysis, the effect of this non-infinite demand elasticity should be kept separate from the supply elasticity. 
increases with $\gamma$, the degree of diminishing returns to labor-or in other words, the convergence rate tends to be greater when labor demand is inelastic. Finally, the convergence rate $\kappa$ is greatest when the fraction of workers employed $\frac{L^{-}}{N^{*}}$ is near 0 or 1 , and has a minimum at an intermediate value of $\frac{L^{-}}{\mathrm{N}^{\circ}}$.

Equation (40) indicates that the long-run elasticity of employment $\beta$ increases with the hourly detection rate $q$ and the weekly wage $w^{*} h^{*}$, and declines with the disutility of effort $\bar{e}$, the false positive rate $c h^{*}$ and the elasticity of weekly hours $\alpha$. If $c h^{*}$ is relatively small, the long-run elasticity of employment decreases with the exogenous quit rate $b$ and is highest when the fraction of workers employed is at an intermediate value.

We can roughly calibrate the convergence rate $\kappa$ and the long-run elasticity of employment 3 . The steady-state unemployment rate $\frac{N^{*}-L^{-}}{N^{-}}$should be $e^{32}$ about .08 , so we can set $\frac{L^{-}}{N^{*}}$ at .92 . For the labor market as a whole, Medoff (1979) finds that separations, excluding layoffs, ${ }^{33}$ occur at a rat $\epsilon$ of about $32 \%$ per year. Guessing that of that $32 \%$ per year, $2 \%$ is due to false positives that lead tc unjust firings and $30 \%$ is due to exogenous separations, we can set $c h^{*}=.02 /$ year and $b=.3 /$ year Assuming an underlying Cobb-Douglas production function, $\gamma$ should be equal to capital's share in output, which is about .333. We can take .2 as our estimate of $\alpha$. The last quantity we need tc know is the ratio $\frac{e}{w^{-} k^{-} q}$, which is the dollar value of the surplus from getting a job divided by the rate of pay. The dollar value of the surplus from getting a job can be gauged either by thinking of how much someone would pay to get a job, or by thinking of how much on-the-job leisure could be taken, how many things could be stolen and how much money could be embezzled, on average before getting fired. For an average job, this surplus might be equal to about two month's worth of pay, so that $\frac{\ell}{w^{*} h^{-} q}=.166$ year. Using these values of the parameters, we find that the three terms comprising $\kappa$ add up to $\kappa \approx(4+.15-.001) /$ year $=4.149 /$ year, which means it would take about two months to get half-way to the new steady state after a permanent shock. The two terms comprising the long-run elasticity of employment come to $\beta \approx .13-.001=.129$, which would be a

32 The appropriate number might be much larger, if the potential labor force includes many people not actively looking for work and therefore not counted as "in the labor force" in the official statistics. If this number is made larger, the results become more like those in the next section.

33 Since we have assumed away layofts in deriving all of our results so far, it is not appropriate to include the layof rate. If the only reason layoffs occurred was because of firms that go out of business according to a Poisson process and lay off all of their workers at once, then the layoft rate could simply be added to $b$ in all of the equations. (Medoff (1979) finds an average layoff rate of about $1.7 \%$ per month or about $20 \%$ per year.) 
modest, but important, addition to the long-run elasticity of labor supply.

One other quantity of some interest is the elasticity of output with respect to changes in $p$. which involves the elasticity of labor demand as well as the elasticity of labor supply. Equations (36) and (38) imply that the short-run elasticity of output with respect to changes in $p$ is

$$
\frac{\ddot{y}(0) / y^{*}}{\ddot{p}(0) / p^{*}}=\frac{w^{*} h^{*} L^{*} \alpha}{p^{*} y^{*}(1+\alpha \gamma)}
$$

and the long-run elasticity of output with respect to changes in $p$ is

$$
\frac{\Delta y / y^{*}}{\Delta p / p^{*}}=\frac{w^{*} h^{*} L^{*}}{p^{*} y^{*}(1+\alpha \gamma)}\left[\alpha+\frac{h^{*} w^{*} q\left(N^{*}-L^{*}\right)}{\kappa(1+\alpha \gamma) \vec{e} L^{*}}-\frac{\alpha c h^{*}}{\kappa(1+\alpha \gamma)}\right] \text {, }
$$

if changes in $p$ represent relative price movements, with 1 to be added to each of these two quantities if changes in $p$ represent productivity movements. Since the quantity $\frac{w^{*} h^{*} L^{-}}{p^{-} y^{*}}$ is just labor's share in output, which we have already set at .667 , we can use the parameters above to estimate these long-run output elasticities as .125 and .199 respectively, plus 1 if productivity movements rather than relative price movements are at issue.

\section{The Dual Labor Market}

As in Bulow and Summers (1986), the model we have been using can be reinterpreted as a model of the dual labor market, with a high-productivity primary sector bedeviled by problems of effort elicitation and a low-productivity secondary sector free of such problems. ${ }^{34}$ Since there is no problem of effort elicitation in the secondary sector, we can assume that it is perfectly competitive, and that in the secondary sector, the number of hours per week is chosen by the workers.

When the word "unemployment" used above is reinterpreted as underemployment (1.e., being employed in the secondary sector when fully qualified to work in the primary sector), the only way in which the results change is that $\bar{w}$-which now represents the flow of utility when in the secondary sector-becomes endogenous. Using the subscript " 2 " to indicate quantities in the secondary sector,

$\tilde{\tilde{w}}(t)=h_{2}^{*} \tilde{w}_{2}(t)=-\gamma_{2} h_{2}^{*} w_{2}^{*}\left(\frac{\bar{L}_{2}(t)}{L_{2}^{*}}+\frac{\tilde{h}_{2}(t)}{h_{2}^{*}}\right)=\frac{\gamma_{2} h_{2}^{*} w_{2}^{*}}{N^{*}-L^{*}} \bar{L}(t)-\alpha_{2} \gamma_{2} h_{2}^{*} \bar{w}_{2}(t)=\frac{\gamma_{2} h_{2}^{*} w_{2}^{*}}{\left(1+\alpha_{2} \gamma_{2}\right)\left(N^{*}-L^{*}\right)} \tilde{L}(t)$

34 We cannot have both a dual labor market and unemployment without expanding the model further, as is done further on in Bulow and Summers (1986). This will be left to the interested reader. 
The first equality holds because of the envelope theorem, the second because of the labor demand function in the secondary sector, the third by substituting in for $\tilde{L}_{2}(t)$ and $\bar{h}_{2}(t)$, and the last equality arises by using the equivalence between the second and fourth expressions to eliminate $\tilde{w}_{2}(t)$. Substituting the expression for $\tilde{\bar{w}}(t)$ given by (44) into (32)-(35), we obtain a variant of (36) without the term involving $\tilde{\bar{w}}(t)$ and with $\kappa$ given by

$$
\kappa=\frac{\left[b+e h^{*}\right] N^{*}}{N^{*}-L^{*}}+\frac{\gamma w^{*} h^{*} q\left(N^{*}-L^{*}\right)}{(1+\alpha \gamma) \bar{e} L^{*}}-\frac{\alpha \gamma c h^{*}}{1+\alpha \gamma}+\frac{\gamma_{2} w_{2}^{*} h_{2}^{*} q}{\left(1+\alpha_{2} \gamma_{2}\right) \bar{e}} .
$$

Thus, the convergence rate $\kappa$ tends to be increased by the fact that drawing workers out of underemployment will raise the wage in the secondary sector. The influence of the secondary sector on the convergence rate in the primary sector increases with the degree of diminishing returns to labor in the secondary sector $\gamma_{2}$, the weekly wage in the secondary sector $w_{2}^{*} h_{2}^{*}$, and the hourly detection rate $q$, and decreases with the elasticity of weekly hours in the secondary sector $\alpha_{2}$ and the disutility of effort $\bar{e}$.

The new expression for the long-run supply elasticity of employment is

$$
\beta=\frac{\frac{h^{*} w^{*} q\left(N^{*}-L^{*}\right)}{\varepsilon L^{*}}-\alpha c h^{*}}{\frac{\left(b+c h^{*} \mid N^{*}\right.}{N^{*}-L^{*}}+\frac{\gamma_{2} w_{2}^{*} h_{2}^{*} q}{\left(1+\alpha_{2} \gamma_{2}\right) \varepsilon}} .
$$

The expressions for the short- and long-run elasticities of output with respect to changes in $p$ are the same as above ((42) and (43)), with the convergence rate $\kappa$ appearing in those expressions being given by (45) instead of by (37). The long-run elasticity of employment $\beta$ tends to be reduced by the fact that drawing workers out of under-employment will raise the wage in the secondary sector, the more so the more $\kappa$ is influenced by this fact.

The most important change in moving to the dual labor market interpretation of the model is in the parameter values that seem appropriate. $\frac{L^{*}}{N^{*}}$ is now the fraction of workers employed in the primary sector, which we can put at .5. Since jobs in the primary sector tend to be more stable than those in the secondary sector, let us reduce the exogenous separation rate $b$ to $.2 /$ year. Let us also raise our estimate of the dollar value of the surplus from the job to four months worth of pay, so that $\frac{e}{w^{*} h^{-q}}=.333$ year. To represent the fact that the primary sector is more capital intensive than the secondary sector, let us raise $\gamma$ to .4 and set $\gamma_{2}$ at .2 . Finally, let us assume that the weekly wage in the secondary sector is half that in the primary sector, or $\frac{w_{2}^{-} h_{2}^{-}}{w^{*} h^{*}}=.5$, and that the elasticity of hours with respect to the wage is the same in both sectors, or $\alpha_{2}=\alpha=.2$. The false positive 
rate $c h^{*}$ can be left the same as before $(.02)$. Then $\kappa \approx(.44+1.112-.001+.289) /$ year $=1.84 /$ year . which means it would take about four-and-a-half months to get half-way to the new steady state after a permanent shock. The long-run elasticity of employment in the primary sector for these parameter values is $\beta \approx 4.114$. Because of this high long-run elasticity of employment, while the short-run elasticity of output with respect to $p$ is only .111 , the long-run elasticity of primary sector output with respect to $p$ is .95-with 1 added to both if it is a productivity shock rather than a relative price change.

The key parameter change in raising the estimates of the lag length and the long-run elasticity of employment above those in the previous section is the reduction in $\frac{L^{-}}{N^{-}}$. Having a large "reserve army" of the underemployed allows for long lags and large movements in primary sector employment.

Of course, since a positive shock to $p$ causes workers to be drawn out of the secondary sector, it will cause a decline in secondary sector output. From (44), we know that

$$
\frac{\tilde{L}_{2}(t)}{L_{2}^{*}}+\frac{\tilde{h}_{2}(t)}{h_{2}^{*}}=\frac{-\tilde{L}(t)}{\left(1+\alpha_{2} \gamma_{2}\right)\left(N^{*}-L^{*}\right)}
$$

so

$$
\frac{\tilde{y}_{2}(t)}{y_{2}^{*}}=\frac{w_{2}^{*} h_{2}^{*} L_{2}^{*}}{p_{2}^{*} y_{2}^{*}}\left[\frac{\tilde{L}_{2}(t)}{L_{2}^{*}}+\frac{\tilde{h}_{2}(t)}{h_{2}^{*}}\right]=-\frac{w_{2}^{*} h_{2}^{*} L_{2}^{*}}{p_{2}^{*} y_{2}^{*}}\left[\frac{\tilde{L}(t)}{\left(1+\alpha_{2} \gamma_{2}\right)\left(N^{*}-L^{*}\right)}\right]
$$

The long-run elasticity of output in the secondary sector with respect to permanent changes in $p$ is then

$$
\frac{\Delta y_{2} / y_{2}^{*}}{\Delta p / p^{*}}=-\frac{w_{2}^{*} h_{2}^{*} L_{2}^{*}}{p_{2}^{*} y_{2}^{*}}\left[\frac{\beta L^{*}}{\left(1+\alpha_{2} \gamma_{2}\right)\left(N^{*}-L^{*}\right)}\right] .
$$

For the parameter values we have been considering, this long-run elasticity of output in the secondary sector with respect to $p$ is about 1.254 (regardless of whether changes in $p$ represent relative price shocks or productivity shocks in the primary sector). Since the shares for labor we have chosen for each sector together with the wage bill in the secondary sector being half that in the primary sector implies that $\frac{p_{i}^{*} y_{i}^{-}}{p^{*} y^{*}}=\frac{.6 .5}{.8}=.375$, we can calculate the short-run elasticity of GNP with respect to changes in $p$ as $\frac{111}{1.375} \approx .081$, since no workers move between sectors in the short run; the long-run elasticity of GNP with respect to changes in $p$ is $\frac{.95-.375 \cdot 1.254}{1.375} \approx .349$-with 
$\frac{1}{1.375} \approx .727$ added to both elasticities if changes in $p$ represent productivity shocks instead of just relative price changes. Thus, even when the reduction in secondary sector output is accounted for, increases in $p$ result in significant increases in GNP under the dual labor market interpretation of the model.

\section{Conclusion}

Shapiro and Stiglitz' (1984) effort elicitation model has been shown to have many intriguing implications for labor market dynamics. To begin with, it has a surprising array of sunspot equilibria driven by extraneous variables. When the dynamic equilibrium with a continuous path of employment is selected out of this array of equilibria on the grounds of realism, the solution continues to exhibit many interesting features. A slow adjustment of employment to labor market shocks is supported by a negative motivational externality of hiring that makes firms reluctant to do substantial hiring at the same time other firms are. The fact that employment does adjust. given time, results in a macroeconomic labor supply elasticity higher than the microeconomic labor supply elasticity of a representative worker.

Adding to this canonical model a decision about weekly hours per worker and interpreting it as a model of the dual-labor market and involuntary underemployment rather than as a model of involuntary unemployment allows us to reproduce many of the major qualitative features of business cycle movements. A reasonable estimate of the convergence rate endogenous to the model under this interpretation indicates lags that are substantial in length when compared to the length of a business cycle (with a half-life of roughly four-and-a-half months) and macroeconomic labor supply elasticities that are quite large (on the order of 4 for the primary sector alone) once these lags play themselves out. Further, under this dual labor market interpretation, the model makes the empirically valid prediction of procyclical upgrading of jobs on a large scale (increases in GNP being associated with workers moving out of the low-paying secondary sector, into the higher-paying primary sector).

Two further aspects of the predicted dynamics of the effort elicitation model may help to provide an empirical test of the model. First, the model predicts that the aggregate rate of hiring should be a key variable in affecting the labor $\operatorname{costs},{ }^{35}$ and therefore the hiring decisions of individual

35 In practice, it may be important to distinguish labor costs from the wage, since the assumption we have made 
firms. Second, the predicted lag length for aggregate labor-market adjustment after shocks and the long-run macroeconomic labor supply elasticity depend in a precise way on the parameters of the model. Since there are many different "labor markets" in the world, separated from each other either by national boundaries or by observable worker characteristics, not only the general magnitude of the adjustment speed and the long-run elasticity of employment predicted by the model, but also the predicted variation in these two quantities across labor markets can be compared to empirically observed adjustment speeds and long-run employment elasticities. As just one example. for reasonable parameter values the model makes the empirically valid prediction that observable subgroups of the population forming labor markets with especially high average unemployment rates will also exhibit especially large variations in unemployment over the business cycle. Another prediction, waiting to be tested, is that, other things being equal, a higher separation rate should be associated with quicker adjustment and smaller long-run elasticities of employment. Many other predictions of that sort can be extracted from the equations above.

One message of the preceding analysis has been only implicit. It is that despite the different assumptions that distinguish efficiency wage models from Real Business Cycle models, both types of models address many of the same questions, and are amenable to many of the same modes of analysis. In the absence of any costs of changing prices, dynamic efficiency wage models are indeed real models of the business cycle that are especially concerned with accounting for involuntary unemployment and underemployment and predicting the consequences of involuntary unemployment and underemployment for the workings of the labor market.

that a firm cannot delay wage payments implicitly owed to its workers may not always be true. When firms can delay wage payments implicitly owed to workers, unobservable labor costs replace wages in all of the equations. 


\section{References}

Ball, Laurence, and David Romer, "Real Rigidities and the Non-Neutrality of Money," NBER working paper \#2432 (October, 1987).

Bulow, Jeremy I. and Lawrence H. Summers, "A Theory of Dual Labor Markets with Application to Industrial Policy, Discrimination and Keynesian Unemployment," Journal of Labor Economics (1986).

Hall, Robert E., "The Voiatility of Employment with Fixed Costs of Going to Work," NBER mimeo (June, 1987).

Hansen, Gary D., "Indivisible Labor and the Business Cycle," Journal of Monetary Economics, 16 (1985): 309-327.

Katz, Lawrence F., "Efficiency Wage Theories: A Partial Evaluation," NBER Macroeconomics Annual (1986): 235-276.

Kydland, Finn E., and Edward C. Prescott, "Time to Build and Aggregate Fluctuations," Econometrica, 50 (1982): 1345-1370.

Long, J. B., and Charles I. Plosser, "Real Business Cycles," Journal of Political Economy, 91 (1983): 39-69.

Medoff, James L., "Layoffs and Alternatives under Trade Unions in U.S. Manufacturing," American Economic Review, 69 (1979): 380-395.

Pencavel, John, "Labor Supply of Men: A Survey," chapter 1 in the Handbook of Labor Economics, edited by Orley Ashenfelter and Richard Layard (North Holland: Amsterdam, 1986): 3-102.

Prescott, Edward C., "Theory Ahead of Business Cycle Measurement," Carnegie-Rochester Conference Series on Public Policy," 25 (Autumn, 1986): 11-44.

Rogerson, R. D., "Indivisible Labour, Lotteries and Equilibrium," Journal of Monetary Economics. 21 (1988): 3-16.

Shapiro, Carl, and Joseph E. Stiglitz, "Equilibrium Unemployment as a Worker Discipline Device," American Economic Review 75 (December, 1984): 1215-1217.

Schelling, Thomas C., The Strategy of Conflict (Harvard: Cambridge, 1960). 
</ref_section> 


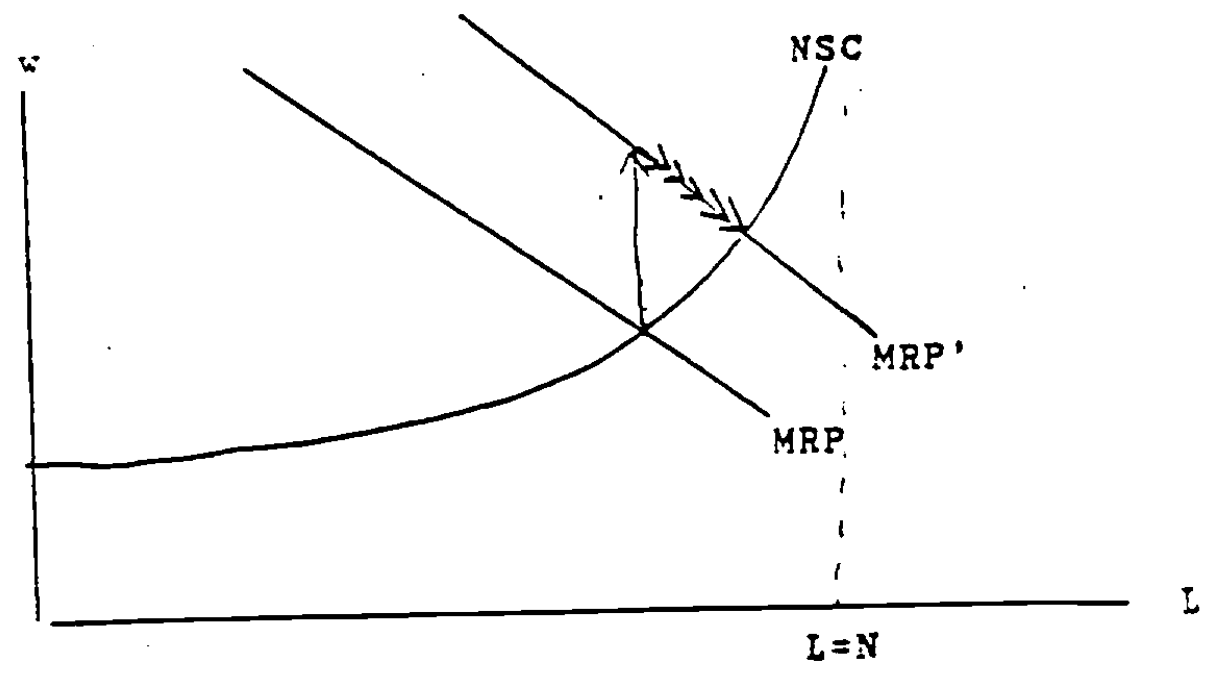

Fig-e 4: Permanent Increase in Demand

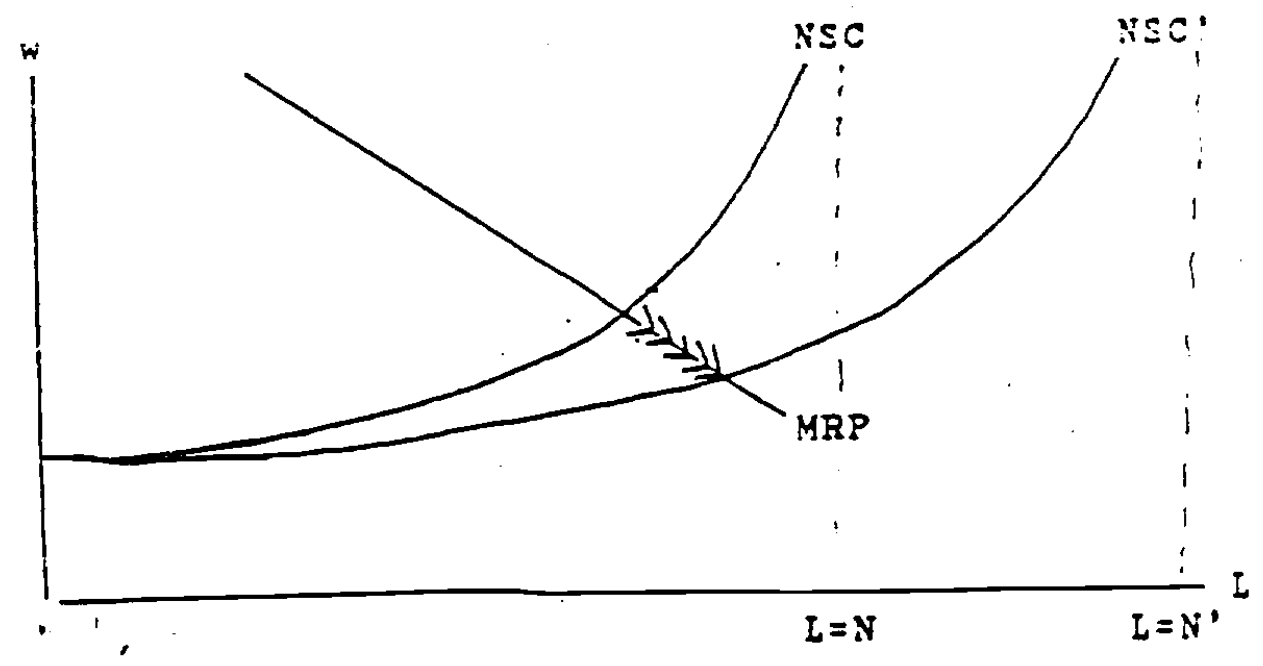

Figure 2: Permadent Increase in Labor Supply

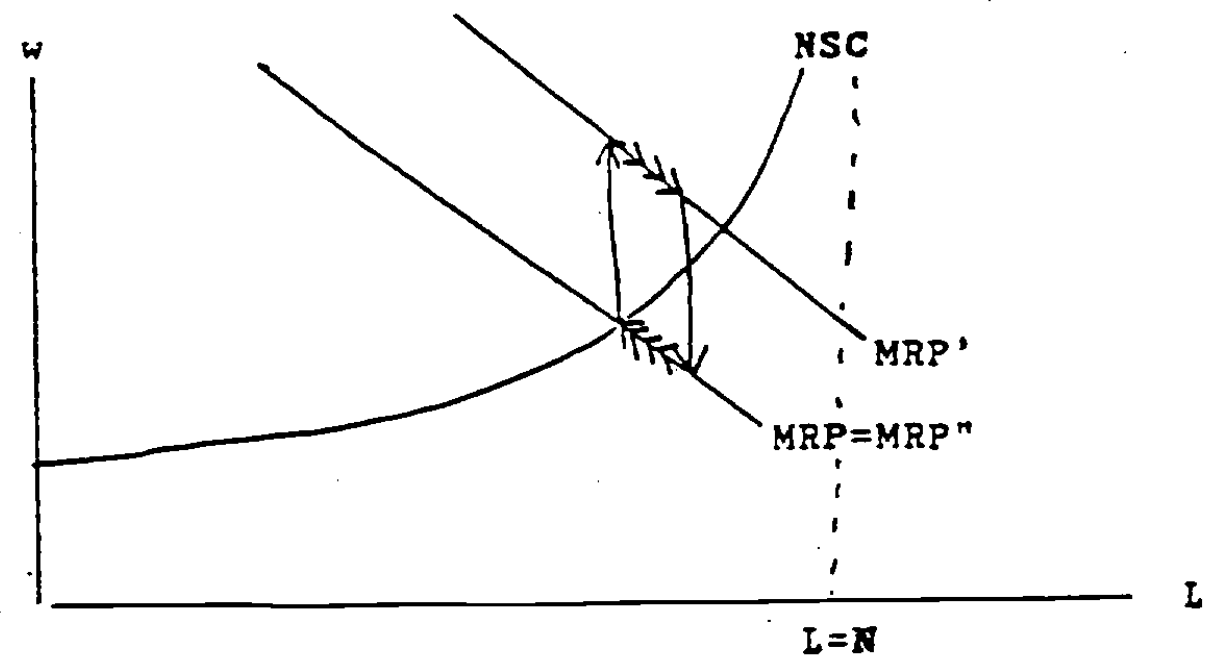

Figure 3: Temporary Increase is Demand 